\title{
ПРОБЛЕМЫ ПРАВОВОГО РЕГУЛИРОВАНИЯ ЗАЛОГА В УГОЛОВНОМ СУДОПРОИЗВОДСТВЕ: ИСТОРИЧЕСКИЙ ОПЫТ И СОВРЕМЕННОЕ СОСТОЯНИЕ
}

Аннотация: Предметом исследования стало правовое регулирование залога как одной из мер пресечения, применяемых в российском уголовном судопроизводстве. Цель работы заключалась в анализе проблем избрания и применения залога. В статье с учетом изменений уголовно-процессуального закона, а также позиций Верховного Суда $Р \Phi$, действующие правовые нормы рассматриваются в исторической взаимосвязи с положениями Устава уголовного судопроизводства 1864 г. На основе изучения судебной и иной статистики проводится анализ эфрективности установления законодателем залоговых сумм в зависимости от тяжести деяния. При проведении исследования применялись следующие методы научного познания: диалектический, исторический, сравнительно-правовой, статистический, логический, метод системно-структурного анализа. Проводится исторический анализ отечественного уголовно-прочессуального законодательства о регламентации порядка избрания меры пресечения в виде залога. Делается вывод о том, что современный законодатель отошел от традиционного регулирования вопроса об определении суммы залога, вносимой в обеспечение явки обвиняемого к лицу, ведущему производство по уголовному делу. В статье ставится проблема установления в УПК РФ экономически необоснованных залоговых сумм, внесение которых для большинства подозреваемых (обвиняемых) весьма проблематично. По мнению автора, для расширения среры применения залога как альтернативы заключению под стражу следует отказаться от установления в законе минимальных размеров залога. Ключевые слова: залог, мера пресечения, Устав уголовного судопроизводства, следователь, обвиняемый, сумма залога, заключение под стражу, судья, подозреваемый, мера процессуального принуждения.

DOI: 10.7256/1994-1471.2014.6.11089

$\Pi$ роводимая в нашем государстве реформа системы исполнения наказаний продиктована в целом негативной ситуацией сложившейся в этой сфере. Количество лиц, отбывающих наказание в виде лишения свободы и ожидающих судебного решения в следственных изоляторах, остается стабильно высоким на протяжении многих лет. Все усилия государства (амнистии, декриминализация отдельных деяний и др.), направленные на снижение численности тюремного населения, пока не имеют должного результата.

УПК РФ предоставляет органам предварительного расследования избрать в отношении обвиняемого (подозреваемого) любую из семи мер пресечения. Более того, следователь имеет право не избирать меру пресечения, ограничившись обязательством о явке, если отсутствует предусмотренные законом основания. Однако на практике в большинстве случаев следователи избирают меру пресечения, и выбор невелик - заключение под стражу или подписка о невыезде и надлежащем поведении. При этом, к сожалению, первично именно заключение под стражу, поскольку эта мера пресечения позволяет следователю в наибольшей степени облегчить себе работу, не опасаясь, что обвиняемый скроется или не явится для производства следственных действий.

(C) Бедняков Иван Львович

Кандидат юридических наук, доцент, кафедра уголовного процесса и криминалистики, ФКОУ ВПО «Самарский юридический институт ФСИН России»

[1981ivan@mail.ru]

443022, Россия, г. Самара, ул. Рыльская, д. 24в.

Материалы Международной научно-практической конференции "Уголовное судопроизводство: история и современность", посвященной 150-летию Устава уголовного судопроизводства Российской империи. 
Рассмотрение судами РФ ходатайств об избрании меры пресечения в виде заключения под стражу (по числу лиц) в тыс. ${ }^{1}$

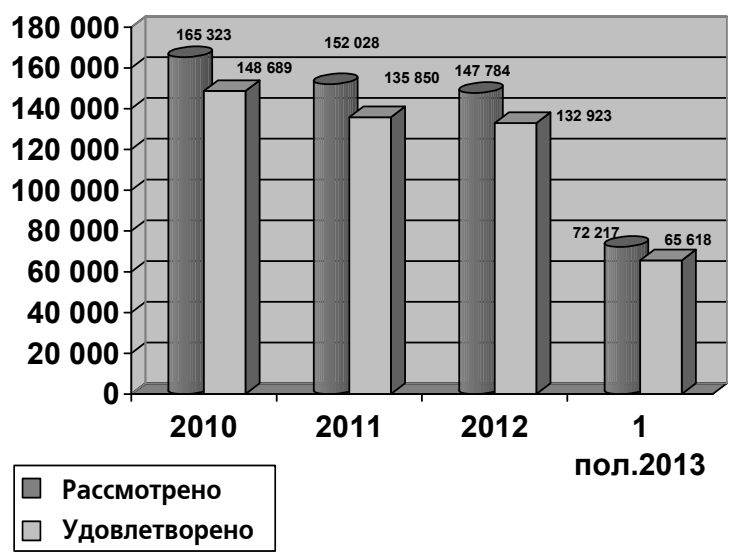

Изучение представленных статистических сведений свидетельствует о тенденции незначительного снижения за последние три года количества рассмотренных (удовлетворенных) судом ходатайств об избрании меры пресечения в виде заключения под стражу. Вместе с тем на достаточно высоком уровне остается процент избрания в отношении обвиняемых наиболее строгой из предусмотренных УПК РФ меры пресечения.

До принятия Судебных Уставов 1864 года отечественное законодательство предусматривало возможность применения полицией для предупреждения побега обвиняемых следующие меры: отдача на поруки, надзор полиции, домашний арест и содержание в тюрьме. Из вышеперечисленных мер применялось в основном взятие под стражу.

Уставом уголовного судопроизводства ${ }^{2}$ была закреплена система мер пресечения, включавшая:

- $\quad$ отобрание вида на жительство или подписки о явке к следствию;

- отдача на поруки;

- отдача под надзор полиции;

- залог;

- д домашний арест;

- $\quad$ взятие под стражу.

П.И. Люблинский классифицировал их на меры, имеющие своим содержанием денежное или имущественное обеспечение, и меры, основанные на личном обеспечении. По его мнению, прогрессивность УУС заключалась в том, что обвиняемый мог избежать помещения в тюрьму, посредством применения к нему дру-

\footnotetext{
Сводные статистические сведения о деятельности федеральных судов общей юрисдикции РФ за 2010-2013 гг (1 полугодие) [Электронный ресурс] // URL: http:// www. cdep.ru/index.php?id=79.html (дата обращения: 15 мая 2014 г.)
}

2 Далее по тексту - УуС. гих мер пресечения. Залог рассматривался как альтернатива содержанию под стражей ${ }^{3}$.

И.Я. Фойницкий отмечал, что стремясь оградить интересы гражданской и личной свободы, Судебные уставы 1864 г. значительно сузили применение личного задержания и дали широкое развитие другим мерам, предполагающим оставление обвиняемых на свободе ${ }^{4}$.

Залог избирался по решению мирового судьи в отношении лиц, обвиняемых в преступлениях, за которые могло быть назначено наказание в виде заключения в тюрьме или крепости, соединенных с лишением некоторых особенных прав и преимуществ (ст. 80, 418 УУС).

В соответствии со ст.79 УУС «залог должен состоять в деньгах или движимом имуществе, и может быть представлен как самим обвиняемым, так и всяким другим лицом».

Сумму залога определял мировой судья, исходя из строгости наказания, угрожающего обвиняемому, а также с учетом материального положения залогодателя. Оговаривалось, что залоговая сумма не может быть менее вознаграждения, отыскиваемого потерпевшим от преступления, если иск его подкрепляется достоверными доказательствами (ст.80, 425 УУС) ${ }^{5}$.

УУС не устанавливал минимальной суммы залога, предоставляя право решения этого вопроса лицу, уполномоченному избирать меру пресечения. Думается, что законодатель сознательно отказался от указания в законе конкретных сумм, предполагая, что такая формализация не позволит правоприменителю использовать залог в отношении широкого круга лиц. Как справедливо указывал И.Я. Фойницкий, «для одних и малая сумма была бы нереальная, для других и большая ничего не значила» ${ }^{6}$.

О принятии залога, в соответствии с требованиями закона, следователь составлял постановление, которое подписывалось как им, так и залогодателем. Копия постановления вручалась заинтересованным лицам. До внесения залоговой суммы обвиняемый подвергался содержанию под стражей или домашнему аресту.

\footnotetext{
Люблинский П.И. Свобода личности в уголовном процессе. Меры обеспечения неуклонения обвиняемого от правосудия. - СПб., 1906. - С. 348.

4 Фойницкий И.Я. Курс уголовного судопроизводства. T.1. - СПб., 1996. - С. 54.

Устав уголовного судопроизводства с позднейшими узаконениями, законодательными мотивами, разъяснениями Прав.Сената и циркулярами министра юстиции / под ред.исп.обяз. Обер-Серкретаря Угол. Кассац. Д-та Прав.Сената М. Шрамченко, помощника Обер-Секр. того же Д-та В.Широковым. - СПб., 1899. - С. 124.

6 Фойницкий И.Я. Указ.соч. Т.2. - С. 371.
} 
В случае если обвиняемый скрывался от следствия и суда, залог расходовался следующим образом: часть денежных средств в размере заявленного иска передавалась потерпевшему, оставшаяся сумма обращалась в доход государства и направлялась на улучшение условий содержания под стражей (ст. 427 УУС).

Если обвиняемый отлучался с места постоянного проживания в то время, когда его присутствие на следствии или суде не требовалось, то это не признавалось уклонением, влекущим негативные правовые последствия.

В случае доказанного факта уклонения обвиняемого от следствия и суда, залог подлежал конфискации. Не имел значения факт принятия залогодателем каких-либо действий, направленных на воспрепятствование незаконным действиям обвиняемого. Залогодателю предоставлялась возможность обращения в суд с заявлением об отказе от принятых на себя обязанностей. В случае удовлетворения такого ходатайства в отношении обвиняемого избиралась иная мера пресечения.

В решении вопроса об определении суммы залога УПК РСФСР 1923 г. и УПК РСФСР 1960 г. принципиально не отличались от УУС. В качестве залога могли быть внесены денежные средства (иное имущество и ценности). Конкретную сумму устанавливало лицо, ведущее производство по уголовному делу (ст. 153-154 УПК РСФСР 1923 г., ст.99 УПК РСФСР 1960 г.).

В УПК РФ 2001 г. регламентация применения залога существенным образом не изменилась. Залоговая сумма устанавливалась лицом, ведущим предварительное расследование (прокурором), либо судом. Впоследствии в УПК РФ были внесены изменения в части передачи суду полномочий по решению вопроса об избрании залога в качестве меры пресечения.

Вместе с тем, несмотря на полуторавековую историю закрепления залога в российском уголовно-процессуальном законодательстве, рассматриваемая мера пресечения в силу различного рода причин не нашла широкого распространения.

Перманентное желание усовершенствовать УПК РФ, в совокупности с необоснованно широким применением заключения под стражу, побудило законодателя обратить внимание на рассматриваемую меру пресечения с точки зрения повышения ее эффективности.

Федеральным законом №60-Ф3 от 07.04.20107 ст.106 УПК РФ была изложена в новой редакции. Нельзя не отметить очевидные

Федеральный закон Российской Федерации от 7 апреля 2010 г. № 60-Ф3 «О внесении изменений в отдельные законодательные акты Российской Федерации»//Российская газета. 09.04.2010. № 5154. достоинства принятых изменений: возможность избрания залога в любой момент производства по делу, рассмотрения ходатайства о залоге наряду с ходатайством о заключении под стражу, использования в качестве залога недвижимого имущества и др. Вместе с тем в действующей редакции, на наш взгляд, содержится положение, фактически блокирующее возможность применения залога к большинству лиц, подозреваемых и обвиняемых в совершении преступлений - установление необоснованно высокой минимальной суммы залога.

Несмотря на то, что закон не содержит прямого указания на применение залога как альтернативы заключению под стражу, есть все основания полагать, что это именно так. По мнению Верховного Суда РФ, «исходя из положений ч.ч.2 и 7 ст.106 УПК РФ во взаимосвязи с положениями ч.5 ст.107 и ч.ч.3 и 7.1 ст.108 УПК РФ решение об избрании меры пресечения в виде залога суд вправе принять не только по результатам рассмотрения ходатайства следователя, согласованного с руководителем следственного органа..., но и по результатам рассмотрения ходатайства, заявленного подозреваемым, обвиняемым, его защитником, законным представителем либо другим физическим или юридическим лицом, а также по результатам обсуждения в судебном заседании возможности применения альтернативных заключению под стражу или домашнему аресту мер пресечения» ${ }^{8}$.

Камнем преткновения для отдельных правоприменителей при избрании залога до принятия вышеуказанного Федерального закона являлась неопределенность в вопросе об исчислении суммы залога. Наконец, законодатель «закрыл» вроде бы эту проблему, обозначив, что минимальная сумма залога по преступлениям небольшой и средней тяжести составляет 100000 рублей, а по тяжким и особо тяжким преступлениям 500000 рублей. Это законоположение, на наш взгляд, является непреодолимым барьером применения залога в отношении большинства подозреваемых (обвиняемых).

Представленная диаграмма в первую очередь свидетельствует о крайне незначительном удельном весе залога в общей структуре мер пресечения. Во-вторых, налицо тенденция неуклонного снижения количества обвиняемых, в отношении которых избиралась рассматриваемая мера пресечения после внесения в УПК РФ изменений, связанных с установлением минимальных залоговых сумм.

\footnotetext{
8 Постановление Пленума Верховного Суда РФ от 19 декабря 2013 г. № 41 «О практике применения судами законодательства о мерах пресечения в виде заключения под стражу, домашнего ареста и залога»//Российская газета. 27.12.2013. № 6270.
} 
Рассмотрение судами РФ ходатайств об избрании меры пресечения в виде залога (по числу лиц)

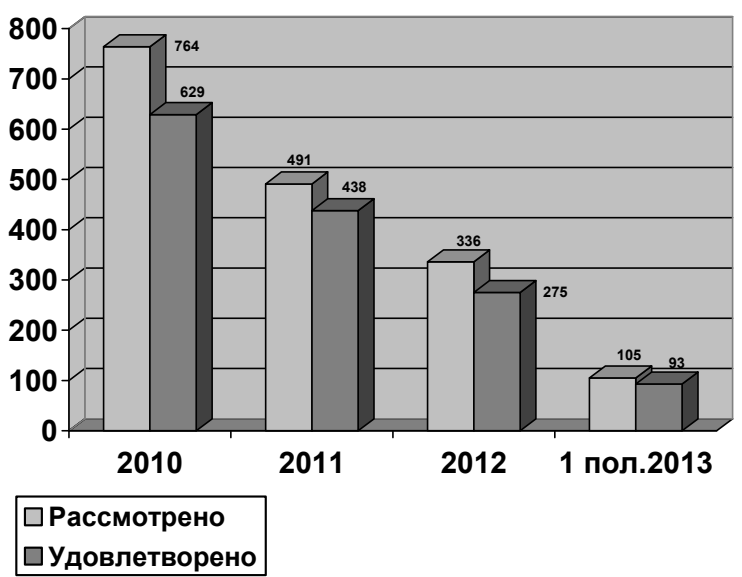

Как показывает статистика, большинство преступлений совершают маргинальные личности, безработные, лица, страдающие алкогольной и наркотической зависимостью, без определенного места жительства и источника дохода и т.п. Так, по данным Росстата на 2013 год, за чертой бедности (т.е. с доходом менее 7429 рублей в месяц) живут около 17,8 млн россиян $(12,6 \%)^{10}$.

Средняя заработная плата по стране в 2013 году составила 23369 рублей. При этом подавляющему большинству граждан этих денег хватает только на повседневные нужды (питание, одежда, обязательные платежи и т.д.). На сбережения у граждан РФ остается лишь 12,2\% доходов, или в среднем примерно 2851 рубль на трудоспособного человека. Исходя из этого среднестатистическому российскому гражданину необходимо почти 3 года, чтобы накопить деньги для внесения залога по преступлениям небольшой и средней тяжести, и 14,5 лет для внесения залога по тяжкому и особо тяжкому преступлению. И это лишь минимальные суммы.

Сказанное подтверждается материалами судебной практики. Постановлением Урайского городского суда Ханты-Мансийского АО от 22.02.2013 мера пресечения в виде заключения под стражу, избранная в отношении обвиняемого Яковлева, была изменена на залог, который должен быть внесен до 13 часов

\footnotetext{
Сводные статистические сведения о деятельности федеральных судов общей юрисдикции РФ за 20102013 г. (1 полугодие) [Электронный ресурс] // URL: http:// www.cdep.ru/index.php?id=79.html (дата обращения: 15 мая 2014 г.)

10 Затраты на рабочую силу и заработная плата в Российской Федерации [Электронный ресурс] // URL: http://www.gks.ru/wps/wcm/connect/rosstat_main/rosstat/ $\mathrm{ru} /$ statistics/wages/.html (дата обращения: 14 февраля 2014 г.)
}

28.02.2013. В установленный судом срок ни обвиняемый, ни иные лица залоговую сумму не внесли, и срок содержания под стражей обвиняемого был продлен на 3 месяца, т.е. до 28.05.2013.

Как следует из определения суда апелляционной инстанции, рассмотревшей жалобу защитника обвиняемого Яковлева, решение суда первой инстанции мотивировано тем, что предварительное следствие по делу окончено, доказательства со стороны обвинения собраны и имеются в материалах уголовного дела, в связи с чем Яковлев не может воспрепятствовать производству по делу, предотвратить возможность скрыться от суда или совершить новые преступления могут и иные меры пресечения, не связанные с заключением под стражу. Суд первой инстанции удовлетворил просьбу защитника об изменении меры пресечения на не связанную с заключением под стражу и принял решение об избрании залога.

Обжаловав решение суда первой инстанции, защитник указал, что избрание в отношении его клиента залога ставит последнего в зависимость от его материального положения, поскольку суду было известно, что у Яковлева нет недвижимости и денежных средств.

Оставляя решение суда первой инстанции без изменений, апелляционный суд в описательно-мотивировочной части решения отметил, что Яковлев обвиняется в трех особо тяжких преступлениях и избрание в отношении него залога является обоснованным, поскольку подписка о невыезде и надлежащем поведении не будет являться достаточной гарантией, обеспечивающей явку подсудимого в судебное заседание ${ }^{11}$.

Однако и в случае изыскания определенной судом залоговой суммы органы предварительного расследования настаивают на заключении обвиняемого под стражу.

Постановлением Брянского районного суда от 24.02.2013 года в отношении обвиняемого по ч.1 ст.30 п. «б» ч.3 ст.228.1 УК РФ К.И.Ф. была избрана мера пресечения в виде залога в сумме 500000 рублей. В удовлетворении ходатайства органов предварительного следствия о заключении К.И.Ф. под стражу было отказано. В установленный судом срок отцом обвиняемого указанная сумма залога была внесена в установленном порядке и К.И.Ф. освобожден из-под стражи.

\footnotetext{
11 Определение суда апелляционной инстанции по уголовным делам суда Ханты-Мансийского автономного округа - Югры от 22.03.2013 [Электронный pecypc] // URL: http://rospravosudie.com/court-sudxanty-mansijskogo-avtonomnogo-okruga-xantymansijskij-avtonomnyj-okrug-s/act-429177256/ (дата обращения: 16 февраля 2014 г.)
} 
Помощником прокурора Брянского района Брянской области вышеуказанное судебное решение было обжаловано.

Судебная коллегия по уголовным делам Брянского областного суда, отменяя решение суда первой инстанции, указала на допущенные при рассмотрении дела процессуальные нарушения. 1. При избрании в отношении К.И.Ф. залога судом были установлены дополнительные ограничения, не предусмотренные ст.106 УПК РФ, а именно: общаться с соучастниками деяния и свидетелями; выходить за пределы территории жилого дома и приусадебного участка и др. 2. В нарушение ч.5 ст.106 УПК РФ залоговая сумма была внесена на депозит не того органа, в производстве которого находилось уголовное дело.

Указав в своем решении на тяжесть деяния, в совершении которого обвиняется К.И.Ф., суд не учел, что до момента апелляционного рассмотрения (13.03.2013, т.е. около 3 недель с момента избрания залога), обвиняемый не скрылся от органов расследования, явился в судебное заседание, а также не совершал действий, препятствующих производству предварительного расследования $^{12}$. Представляется, что в приведенном примере суд апелляционной инстанции необоснованно проигнорировал аргументы стороны защиты и вполне мог бы устранить допущенные судом первой инстанции нарушения, оставив избранную им меру пресечения в отношении обвиняемого К.И.Ф.

Вызывает удивление соотношение минимального размера залога с видами и размерами наказаний за конкретные преступления. Так, за совершение кражи на сумму до 2500 рублей предусмотрена возможность избрания залога на сумму в 100000 рублей, что в 40 раз превышает сумму похищенного. За хищение на сумму до 250000 рублей, можно также избрать залог в сумме 100000 рублей.

Рассмотрим в качестве примера одно из распространенных тяжких преступлений. Двое преступников с применением насилия, не опасного для жизни и здоровья, открыто похитили у пострадавшего 1000 рублей. Минимальная сумма залога для этих лиц составит 500000 рублей. При том, что за это преступление предусмотрено наказание в виде максимального штрафа в 10000 рублей (в 50 раз меньше), либо дохода осужденного за 1 месяц.

По данным МВД РФ, в структуре тяжких и особо тяжких преступлений преобладают

12 Определение судебной коллегии по уголовным делам Брянского областного суда от 13.03.2013 [Электронный ресурс] // URL: http://rospravosudie.com/ court-bryanskij-oblastnoj-sud-bryanskaya-oblast-s/act422561715/ (дата обращения: 16 февраля 2014 г.) различные виды хищений (кражи, грабежи, разбои, вымогательства), а также преступления, связанные с незаконным оборотом наркотиков. Совершают же эти преступления, в основном, лица без определенного источника дохода. По данным МВД РФ, среди 924400 лиц, совершивших преступления в январе-ноябре 2013 году на территории РФ, не имели постоянного источника дохода $65,9 \%$. При том что ситуация по отдельным регионам просто катастрофическая. Доля таких лиц в Дагестане составила 83,7\%, в Северной Осетии 83,5\%, в Ингушетии 83,2\%, в Чеченской Республике $82,4 \%{ }^{13}$. Из вышесказанного напрашивается вывод. Установление минимального размера залога в 100000 и 500000 рублей является ошибкой законодателя.

Что делать в такой ситуации следователю? Выбор невелик. Во-первых, в отношении подозреваемого (обвиняемого) можно не избирать меру пресечения. Однако на практике такие случаи достаточно редки. Даже по преступлениям небольшой и средней тяжести дознаватели (следователи) стараются избирать подписку о невыезде и надлежащем поведении, чтобы хоть как-то воздействовать на подозреваемого (обвиняемого).

Во-вторых, избрать в качестве меры пресечения подписку о невыезде и надлежащем поведении - это наиболее простой, но далеко не самый эффективный выбор. Никаких удерживающих факторов, кроме морально-психологических, такая мера пресечения не имеет. В лучшем случае обвиняемые периодически не являются к следователю, в худшем - используют эту меру пресечения, чтобы скрыться от правосудия. И в том, и в другом случае налицо отрицательные последствия: затягиваются сроки предварительного расследования, следователь вынужден выполнять дополнительную работу по обеспечению явки обвиняемого, привлекаются сотрудники органа дознания для его розыска и т.д.

В-третьих, избрать меру пресечения в виде заключения под стражу, тем более, что судьи охотно удовлетворяют такие ходатайства следователей. В этом случае обвиняемый никуда не скроется, будет являться по вызовам следователя, да и воспрепятствовать производству по делу иным образом вряд ли сможет. Просто и надежно. Но эффективно ли? С точки зрения следователя - весьма эффективно. С точки зрения обвиняемого (его родственников и близких), а

\footnotetext{
Краткая характеристика состояния преступности в Российской Федерации за январь-ноябрь 2013 года [Электронный ресурс] // URL: http://mvd.ru/Deljatelnost/ statistics/reports/item/1388663/ (дата обращения: 15 января 2014 г.)
} 
на наш взгляд и потерпевшего, нет. Говорить о минусах такого положения для обвиняемого излишне. А в чем же «проигрывает» потерпевший? Находясь под стражей, обвиняемый лишается работы, источника дохода, который мог быть направлен на возмещение причиненного потерпевшему вреда. Увеличиваются сроки уголовного судопроизводства, и момент назначения наказания еще более удаляется от момента совершения преступления. Находясь в заключении и осознавая, что в государстве отсутствует нормально работающая система исполнительного производства в части взыскания причиненного вреда, а наиболее вероятное наказание будет связано с лишением свободы (реальным или условным), обвиняемый утрачивает всяческое желание участвовать в примирительных процедурах, возмещении ущерба.

Для следователя плюсы от применения к обвиняемому залога видятся в следующем. Поскольку мера пресечения является одним из средств обеспечения уголовного судопроизводства, то вряд ли следователи заинтересо- ваны в том, чтобы заключить под стражу всех и каждого. Им необходимо, чтобы подозреваемый (обвиняемый): проживал по указанному адресу, являлся по первому вызову к следователю, не препятствовал производству по уголовному. К тому же, избрание в качестве меры пресечения залога, на наш взгляд, позволит избежать многих конфликтных ситуаций между следователем и стороной защиты.

Для обеспечения нормального хода уголовного судопроизводства должен присутствовать определенный фактор, удерживающий подозреваемого (обвиняемого) от совершения новых преступлений и иных противоправных действий, влияющих на процесс расследования. Полагаем, что залог, в отличие от заключения под стражу, обладает всеми качествами, которые позволят найти компромисс между интересами сторон обвинения и защиты.

Вместе с тем чтобы залог не превратился в привилегию для узкого круга лиц, необходимо отказаться от существующего в законе его минимального размера.

\section{Библиография:}

1. Люблинский П.И. Свобода личности в уголовном процессе. Меры обеспечения неуклонения обвиняемого от правосудия. - СПб.: Сенатская типография, 1906. - 711 с.

2. Фойницкий И.Я. Курс уголовного судопроизводства. Т.1. - СПб.: Альфа, 1996. - 552 с.

3. Фойницкий И.Я. Курс уголовного судопроизводства. Т.2. - СПб.: Альфа, 1996. - 606 с.

4. Мельников В.Ю. Права личности в уголовном процессе // Актуальные проблемы российского права. - 2013. - 1. - С. 84-90.

5. О. Н. Селедникова Особенности залога как меры пресечения имущественного характера // Политика и Общество. - 2012. - 7. - С. 87-92.

\section{References:}

1. Lyublinskii P.I. Svoboda lichnosti v ugolovnom protsesse. Mery obespecheniya neukloneniya obvinyaemogo ot pravosudiya. - SPb.: Senatskaya tipografiya, 1906. - $711 \mathrm{~s}$.

2. Foinitskii I.Ya. Kurs ugolovnogo sudoproizvodstva. T.1. - SPb.: Al'fa, 1996. - 552 s.

3. Foinitskii I.Ya. Kurs ugolovnogo sudoproizvodstva. T.2. - SPb.: Al'fa, 1996. - 606 s.

4. Mel'nikov V.Yu. Prava lichnosti v ugolovnom protsesse // Aktual'nye problemy rossiiskogo prava. 2013. - 1. - C. 84-90.

5. O. N. Selednikova Osobennosti zaloga kak mery presecheniya imushchestvennogo kharaktera // Politika i Obshchestvo. - 2012. - 7. - C. 87-92. 